\title{
Changes in IP3 Receptor Expression and Function in Aortic Smooth Muscle of Atherosclerotic Mice
}

\author{
Marie-Ann Ewart ${ }^{\mathrm{a}} \quad$ Azizah Ugusman $^{\mathrm{a}, \mathrm{c}}$ Anisha Vishwanath ${ }^{\mathrm{a}}$ \\ Tarek A.M. Almabrouk ${ }^{a}$ Husam Alganga ${ }^{a}$ Omar J. Katwan ${ }^{a}$ \\ Pavlina Hubanova ${ }^{a}$ Susan Currie ${ }^{b}$ Simon Kennedy ${ }^{a}$ \\ ${ }^{a}$ Institute of Cardiovascular and Medical Sciences, College of Medical, Veterinary and Life Sciences, University of \\ Glasgow, and b Strathclyde Institute of Pharmacy and Biomedical Sciences, Strathclyde University, Glasgow, UK; \\ 'Department of Physiology, Faculty of Medicine, National University of Malaysia Medical Centre, \\ Kuala Lumpur, Malaysia
}

\section{Keywords}

Peroxynitrite - IP3 receptor - Potassium channel .

Atherosclerosis · Aorta

\begin{abstract}
Peroxynitrite is an endothelium-independent vasodilator that induces relaxation via membrane hyperpolarization. The activation of IP3 receptors triggers the opening of potassium channels and hyperpolarization. Previously we found that relaxation to peroxynitrite was maintained during the development of atherosclerosis due to changes in the expression of calcium-regulatory proteins. In this study we investigated: (1) the mechanism of peroxynitrite-induced relaxation in the mouse aorta, (2) the effect of atherosclerosis on relaxation to peroxynitrite and other vasodilators, and (3) the effect of atherosclerosis on the expression and function of the IP3 receptor. Aortic function was studied using wire myography, and atherosclerosis was induced by fat-feeding ApoE ${ }^{-/-}$mice. The expression of IP3 receptors was studied using Western blotting and immunohistochemistry. Relax-
\end{abstract}

\section{KARGER}

E-Mail karger@karger.com www.karger.com/jvr ation to peroxynitrite was attenuated by the IP3 antagonists 2-APB and xestospongin $C$ and also the $K_{v}$ channel blocker 4-aminopyridine (4-AP). Atherosclerosis attenuated vasodilation to cromakalim and the AMPK activator A769662 but not peroxynitrite. Relaxation was attenuated to a greater extent by 2-APB in atherosclerotic aortae despite the reduced expression of IP3 receptors. 4-AP was less effective in $\mathrm{ApoE}^{-/-}$mice fat-fed for 4 months. Peroxynitrite relaxation involves an IP3-induced calcium release and $\mathrm{K}_{\mathrm{V}}$ channel activation. This mechanism becomes less important as atherosclerosis develops, and relaxation to peroxynitrite may be maintained by increased calcium extrusion.

(C) 2017 The Author(s)

Published by S. Karger AG, Basel

\section{Introduction}

The cytosolic concentration of calcium is the primary determinant of the contractile state of the vascular smooth muscle cell (VSMC). Cytosolic calcium levels can be increased via entry across the plasma membrane through

Dr. Simon Kennedy

Institute of Cardiovascular and Medical Sciences

College of Medical, Veterinary and Life Sciences, University of Glasgow

University Avenue, Glasgow G12 8QQ (UK)

E-Mail simon.kennedy@glasgow.ac.uk 
voltage-operated calcium channels [1] or non-selective cation channels or via store-operated calcium entry (SOCE) [2]. An increase in calcium can also occur via release from the intracellular sarcoplasmic reticulum (SR) through intracellular calcium channels, namely IP3 receptors (IP3R) and ryanodine receptors.

Direct activation of IP3R present on the SR by the second messenger inositol 1,4,5-triphosphate results in calcium release and increased global cytosolic $\mathrm{Ca}^{2+}$. Indirect activation of ryanodine receptors resulting from a global increase in cytosolic $\mathrm{Ca}^{2+}$ results in a further $\mathrm{Ca}^{2+}$ release (albeit a small release in comparison to $\mathrm{IP}_{3} \mathrm{R}$ contribution) and the combined effect leads to smooth muscle cell (SMC) contraction. Interestingly, in the last 10 years, it has become apparent that IP3R can communicate locally with plasma membrane channels such as transient receptor potential canonical 3 and large-conductance $\mathrm{Ca}^{2+}$-activated potassium channels $\left(\mathrm{BK}_{\mathrm{Ca}}\right)[\mathrm{re}-$ viewed in 3].

Activation of IP3R renders the $\mathrm{BK}_{\mathrm{Ca}}$ channel more sensitive to calcium in vascular smooth muscle [4], leading to membrane hyperpolarization which may serve to limit contractility in response to IP3R activation. $\mathrm{BK}_{\mathrm{Ca}}$ channels are abundantly expressed in blood vessels and it has been suggested that this may be the switch that decides whether vasoactive factors induce vasoconstriction (via $\mathrm{Ca}^{2+}$ signalling) or vasorelaxation (via membrane hyperpolarization). Indeed, a recent study found that IP3 activated $\mathrm{BK}_{\mathrm{Ca}}$ in porcine coronary SMC with a resultant decrease in vessel tone [5]. Taken together, these studies highlight the pivotal role that IP3R play in modulating $\mathrm{Ca}^{2+}$ handling and vascular contractility in the healthy animal.

Peroxynitrite $\left(\mathrm{ONOO}^{-}\right)$is a reaction product of nitric oxide and superoxide and as such it has been detected in increased quantities in the arterial wall of atherosclerotic mice [6] and also in the plasma of human subjects with acute coronary syndrome [7]. In healthy vessels, $\mathrm{ONOO}^{-}$ induces endothelium-independent relaxation [8] through elevation of cGMP levels, membrane hyperpolarization, and direct activation of myosin phosphatase activity in smooth muscle. Vasodilation also involves calcium regulatory proteins, with increases in SERCA activity seen in artery homogenates in response to $\mathrm{ONOO}^{-}[9]$. However, to date there is no information on how IP3R-induced calcium release and membrane hyperpolarization via potassium channel activation are involved in $\mathrm{ONOO}^{-}$-induced relaxation.

In a previous study we demonstrated that arterial relaxation to $\mathrm{ONOO}^{-}$was maintained in atherosclerotic
ApoE $\mathrm{E}^{-/-}$mice fed a high-fat diet for up to 4 months, despite downregulation of SERCA expression and function in VSMC. We concluded that upregulation at the protein level of the calcium-extruding PMCA compensates for the effect of atherosclerosis on SERCA and maintains vascular relaxation under atherogenic conditions. However, the role of IP3R in maintaining relaxation to $\mathrm{ONOO}^{-}$in this pathology is not well understood. In hypercholesterolaemic mice without evidence of atherosclerotic plaques, the intracellular calcium $\left[\mathrm{Ca}^{2+}\right]_{\mathrm{i}}$ in aortic VSMC was increased due to augmented IP3R-mediated SOCE rather than an enhanced SR calcium release [10], and this may be related to changes in plasma membrane cholesterol in response to raised plasma lipid levels [11]. Although very few other studies have examined IP3R function in atherosclerosis, there is evidence in hypertensive mice and rats that IP3R transcript and protein levels are raised in mesenteric resistance vessels [12]. In hypertensive animals, pharmacological experiments have also revealed that IP3-mediated calcium release contributes more to contraction compared to control animals. Increased pulsatile pressure applied to rat VSMC in vitro also increased cell migration and this occurred via IP3R since it was blocked by the IP3R blockers 2-APB and xestospongin C [13]. These studies support the likelihood that IP3R function in vascular smooth muscle may be altered under pathophysiological conditions and may result in altered SOCE as well as SR $\mathrm{Ca}^{2+}$ handling. Changes in SOCE in pathological conditions may also affect other $\mathrm{Ca}^{2+}$ channels. For example, recently discovered channels such as the Orai family, which regulates calcium entry in response to store depletion, may be particularly important in disease states [14].

In this study, we investigated the mechanism of $\mathrm{ONOO}^{-}$relaxation in mouse aortic rings and also studied the effect of developing atherosclerosis on IP3R expression and vascular function in response to $\mathrm{ONOO}^{-}$and other endothelium-independent vasodilators.

\section{Materials and Methods}

Animal Model and Artery Preparation

The mice used in this study were housed at the University of Glasgow and maintained on 12-h cycles of light and dark and at ambient temperature. Initial experiments to study the mechanism of relaxation induced by $\mathrm{ONOO}^{-}$used male C57BL/6 mice (18$23 \mathrm{~g}$, supplied by Harlan). To study the effect of developing atherosclerosis, male $\mathrm{ApoE}^{-/-}$mice (17-38 g, bred in-house) and genetic background control mice (C57BL/6; 18-34 g) were used. C57BL/6 mice were fed a standard chow diet while $\mathrm{ApoE}^{-/-}$mice 
commenced a high-fat diet ( $21 \%$ lard and $0.15 \%$ cholesterol; SDS) at 8 weeks of age which was continued for between 2 and 4 months. Age-matched C57 mice were used in all experiments. To assess the effects of ApoE gene knockout alone, some experiments also used chow-fed $\mathrm{ApoE}^{-/-}$mice. Procedures conformed to the Guide for the Care and Use of Laboratory Animals published by the US National Institutes of Health (NIH publication No. 85-23, revised in 1996) and Directive 2010/63/EU of the European Parliament. Mice were terminally anaesthetized via intraperitoneal injection of sodium pentobarbital $(200 \mathrm{mg} / \mathrm{mL})$ and the thoracic aorta was removed to ice cold oxygenated $\left(95 \% \mathrm{O}_{2}: 5 \% \mathrm{CO}_{2}\right)$ Krebs' solution for preparation.

\section{Small Vessel Wire Myography}

The thoracic aorta was cleaned of all fat and connective tissue and cut into 2-mm rings. In some experiments the endothelium was left intact but in the majority of cases it was removed by gently rubbing the lumen of the vessel with a piece of fine wire. Artery rings were mounted on 2 stainless steel pins in a 4-channel wire myograph (Danish Myo Technology), set to an optimum tension of $9.8 \mathrm{mN}$ [15], and allowed to equilibrate for at least $30 \mathrm{~min}$ before use. Vessels were bathed in Krebs' buffer with the following composition: $118 \mathrm{mM} \mathrm{NaCl}, 4.7 \mathrm{mM} \mathrm{KCl}, 1.2 \mathrm{mM} \mathrm{MgSO}_{4}, 25 \mathrm{mM}$ $\mathrm{NaHCO}_{3}, 1.03 \mathrm{mM} \mathrm{KH}_{2} \mathrm{PO}_{4}, 11 \mathrm{~mm}$ glucose, and $2.5 \mathrm{mM} \mathrm{CaCl}_{2}$ at $37^{\circ} \mathrm{C}$ and gassed continuously with $95 \% \mathrm{O}_{2}$ and $5 \% \mathrm{CO}_{2}$. Reproducible responses to $40 \mathrm{mM} \mathrm{KCl}$ (typically 2 separate additions per ring) were obtained and then rings were contracted to $30 \mathrm{nM}$ 9,11-dideoxy-9a,11 $\alpha$-methanoepoxy prostaglandin $\mathrm{F}_{2 \alpha}$ (U46619; Tocris) and successful removal of the endothelium was confirmed by the lack of $(<10 \%)$ a vasodilator response to $10^{-6} \mathrm{M}$ acetylcholine. Rings were then washed, antagonists were added, and contraction was induced a second time by addition of $30 \mathrm{nM}$ U46619, and once the level of contractile force had stabilized (typically 15-20 $\mathrm{min}$ ) the experiments were commenced. This allowed the contractile responses and the effect of $2-\mathrm{APB}$ in $\mathrm{C} 57 \mathrm{BL} / 6$ and $\mathrm{ApoE}^{-1-}$ mice to be compared.

In pre-contracted rings, dose response curves were constructed to 3 different vasodilators: (1) $\mathrm{ONOO}^{-}$(Calbiochem) used in the range $1 \times 10^{-6}-5 \times 10^{-4} \mathrm{M}$, and $\mathrm{ONOO}^{-}$was diluted in argonpurged $\mathrm{dH}_{2} \mathrm{O}$ and kept in the dark at $4^{\circ} \mathrm{C}$; (2) cromakalim (SigmaAldrich), an activator of $\mathrm{K}_{\mathrm{ATP}}$ channels on VSMC, was used in the concentration range $1 \times 10^{-9}-5 \times 10^{-6} \mathrm{M}$, and cromakalim was dissolved in DMSO and diluted in Krebs'; and (3) the AMPK activator A769662 [6,7-dihydro-4-hydroxy-3-(2'-hydroxy[1, 1'-biphenyl]-4-yl)-6-oxo-thieno(2, 3-b)pyridine-5-carbonitrile; Tocris]. A769662 was dissolved in DMSO, diluted in Krebs', and used in the range $1 \times 10^{-6}-5 \times 10^{-4} \mathrm{M}[16]$. All 3 vasodilators were added at 10 -min intervals. To study the involvement of the IP3R, rings were pre-incubated with the IP3R antagonists 2-aminoethoxydiphenyl borate (2-APB; $60 \mu \mathrm{M}$; Tocris) or xestospongin $\mathrm{C}$ ( 0.5 or $5 \mu \mathrm{M}$; Cayman Chemical Company) for $30 \mathrm{~min}$ before the addition of vasodilators. Xestospongin $\mathrm{C}$ is a much more potent and selective IP3R antagonist that is effective at low micromolar concentrations [17].

To study the involvement of potassium channels which may be activated by a IP3R-induced calcium release, aortic rings were incubated with: the general $\mathrm{Ca}^{2+}$-activated potassium channel blocker tetraethylammonium chloride (TEA, $1 \mathrm{mM}$; Sigma-Aldrich), the $\mathrm{K}_{\mathrm{v}}$ channel blocker 4-aminopyridine (4-AP, $1 \mathrm{mM}$; Sigma-Aldrich), the ATP-sensitive potassium channel blocker gliben- clamide (0.3 $\mu \mathrm{M}$; Sigma-Aldrich), or the $\mathrm{BK}_{\mathrm{Ca}}$-selective channel blocker iberiotoxin (100 nM; Latoxan, Portes les Valance, France). All were incubated for $30 \mathrm{~min}$ before contraction to U46619. For all experiments, data were expressed as a percentage relaxation of the U46619-induced tone.

\section{Histological Analysis}

Cleaned thoracic aortae were fixed in neutral-buffered formalin and embedded in paraffin and $4-\mu \mathrm{m}$ sections were cut on a rotary microtome. IP3R (IP3R1) was detected in sections using a rabbit polyclonal IP3R (type 1) antibody (1:1,000 dilution, Ab5804; Abcam) and visualized using biotin-labelled secondary antibodystreptavidin-HRP complexes and a DAB (3,3' diaminobenzidine) chromogenic substrate (Vector Laboratories). Images were analysed blindly by 2 independent observers and the degree of staining was quantified using ImageJ software.

\section{Protein Expression/Immunoblotting}

Denuded aortae were pulverized in liquid nitrogen, re-suspended in ice-cold cell lysis buffer ( $50 \mathrm{mM}$ Tris [pH 7.4], $50 \mathrm{mM}$ $\mathrm{NaF}, 1 \mathrm{mM} \mathrm{Na}{ }_{4} \mathrm{PPi}, 1 \mathrm{~mm}$ EGTA, 1 mM EDTA, 1\% Triton X-100, $1 \mathrm{mM}$ DTT, and $1 \%$ cocktail of protease inhibitors) and protein concentrations determined using Coomassie Plus Protein Assay Reagent (Perbio, USA). Homogenates were run at several protein concentrations $(2.5,5$ and $7.5 \mu \mathrm{g} /$ lane $)$ on NuPAGE Novex $4-12 \%$ Bis-Tris mini gels (Life Technologies) and transferred to a nitrocellulose membrane, and IP3R was detected using rabbit polyclonal anti-IP3R1 (No. 3763 used at 1:1,000; Cell Signaling Technology). Large conductance calcium-activated potassium channels $\left(\mathrm{BK}_{\mathrm{Ca}}\right)$ in lysates were detected using an anti $\mathrm{BK}_{\mathrm{Ca}}$ mouse monoclonal antibody (1:500 dilution, ab99046; ABcam). Secondary HRP-conjugated antibodies were either goat anti-rabbit HRP conjugated for IP3 detection (ab6721; Abcam) or rabbit antimouse HRP conjugated for $\mathrm{BK}_{\mathrm{Ca}}$ detection (ab6728; Abcam). IP3R and $\mathrm{BK}_{\mathrm{Ca}}$ protein abundance was quantified using Quantity One software (BioRad). Expression was normalized to GAPDH (1:40,000. No. G8795; Sigma-Aldrich) or a-actin (1:1,000, No. 14958; Cell Signaling Technology).

\section{Statistical Analysis}

All results are presented as means \pm SEM, and $n$ represents the number of mice used for each experiment. Myography data were analysed via GraphPad Prism software and significance was determined using 2-way ANOVA which compares the full dose-response curves. The area under the curve was used to analyse differences in the inhibitory effect of 2-APB in control and ApoE $\mathrm{E}^{-/-}$ mice [18]. Student's $t$ tests (unpaired) were performed on IP3R or $\mathrm{BK}_{\mathrm{Ca}}$ expression data. In all cases, $p<0.05$ was considered statistically significant.

\section{Results}

\section{Relaxation to $\mathrm{ONOO}^{-}$in $\mathrm{C} 57 \mathrm{BL} / 6$ Aortic Rings}

Peroxynitrite induced a dose-dependent vasodilation of a similar magnitude in endothelium-intact and denuded thoracic aortae from $\mathrm{C} 57 \mathrm{BL} / 6$ mice (the maximum relaxation at $500 \mu \mathrm{M} \mathrm{ONOO}^{-}$was $81.2 \pm 3.8 \%$ in 


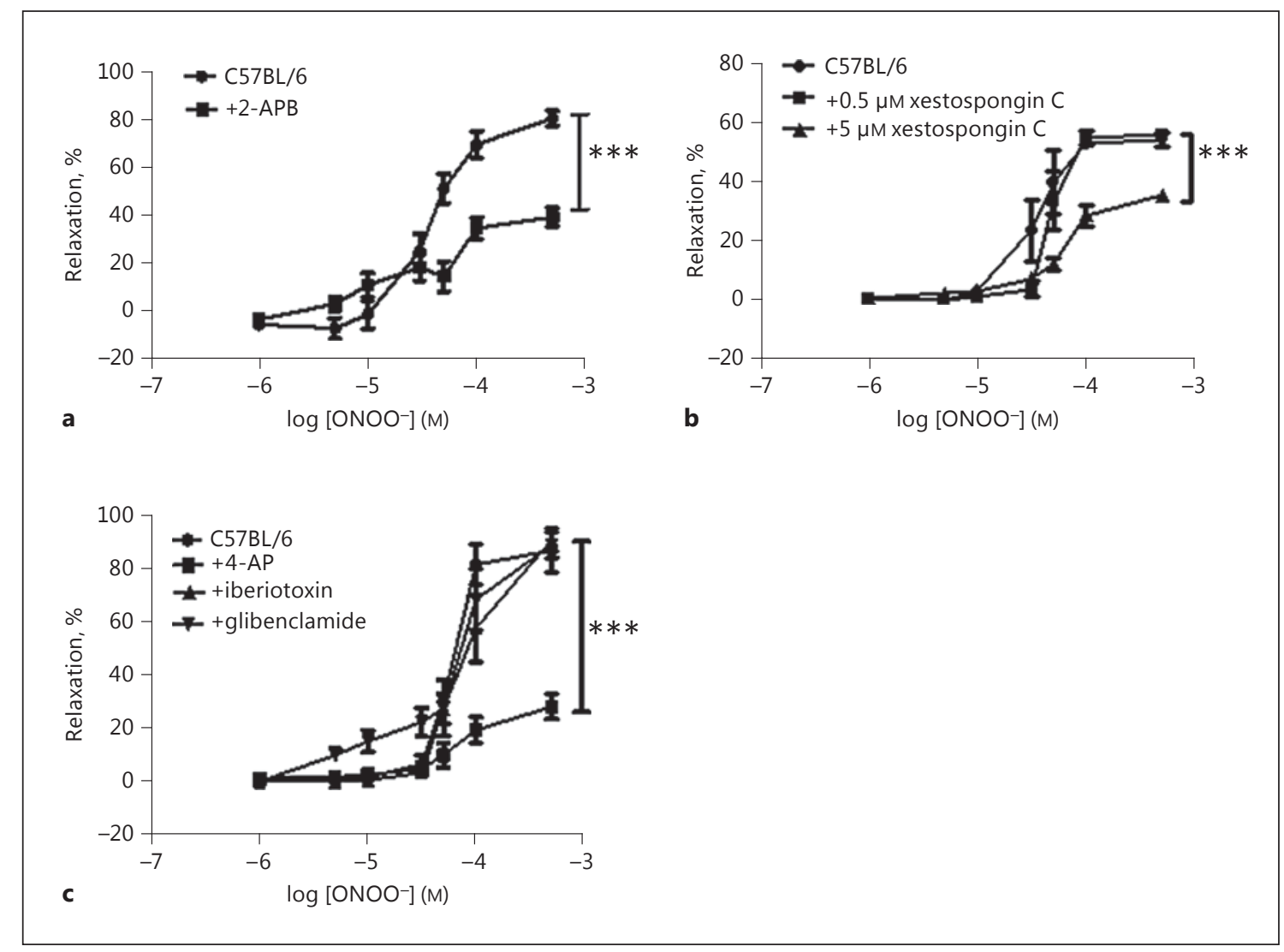

Fig. 1. a In denuded C57BL/6 mouse aortic rings, the IP3 receptor antagonist 2-APB $(60 \mu \mathrm{M})$ significantly reduced relaxation to peroxynitrite. $\mathbf{b}$ Another IP3 receptor antagonist, xestospongin C showed a dose-dependent effect, blocking relaxation to peroxynitrite at $5 \mu \mathrm{M}$. c Relaxation to peroxynitrite was significantly reduced by 4 -AP but not other potassium channel blockers. ${ }^{* * *} p<0.001$ vs C57BL/ 6 control group, $n>5$ for all groups.

intact aortae vs. $80.5 \pm 4.1 \%$ in denuded aortae; $n=8-10$; $p=\mathrm{ns})$. Pre-incubation with $60 \mu \mathrm{M} 2$-APB caused a significant reduction in the relaxation to $\mathrm{ONOO}^{-}$in denuded aortic rings (Fig. 1a) and this effect was also seen in endothelium-intact rings (the maximum relaxation in intact rings was $91.9 \pm 10.1 \%$ vs. $65.1 \pm 10.1$ in the presence of 2 -APB, $n=3$ for both groups; $p<0.05$ vs. control). Since the focus of this study was on the effects of high-fat feeding on vascular smooth muscle function, all subsequent experiments were performed in denuded aortic rings. Xestospongin $\mathrm{C}$ had no effect on relaxation to $\mathrm{ONOO}^{-}$when added at $0.5 \mu \mathrm{M}$ but it significantly reduced relaxation at a concentration of $5 \mu \mathrm{M}$ (Fig. 1b). To investigate whether relaxation to $\mathrm{ONOO}^{-}$involved potassium channels, several inhibitors were studied. Neither glibenclamide nor iberiotoxin had any effect, but 4-AP significantly attenuated the relaxation to $\mathrm{ONOO}^{-}$ (Fig. 1c).

IP3R and Atherosclerosis

\section{Effect of High-Fat Feeding on Vessel Function}

In a previous study we demonstrated increased nitrotyrosine expression in the thoracic aorta of $\mathrm{ApoE}^{-/-}$mice, particularly in medial and adventitial areas around atherosclerotic plaques, and this effect was more marked with time spent on a high-fat diet [6]. We hypothesized that nitration may affect smooth muscle function by modifying calcium-handling proteins within the cells and here we studied the effect of development of atherosclerotic lesions on IP3R expression and function. We found previously that the relaxation to $\mathrm{ONOO}^{-}$in denuded aortic rings was largely maintained over 5 months of fatfeeding in $\mathrm{ApoE}^{-/-}$mice compared to age-matched C57 controls [6] and also in $\mathrm{ApoE}^{-/-}$mice fed a chow diet for 4 months ( $n=6$; data not shown). As with C57 mice, preincubation of $\mathrm{ApoE}^{-/-}$aortic rings with 2-APB caused a significant reduction of $\mathrm{ONOO}^{-}$-induced relaxation. In order to compare the inhibitory effect of 2-APB in C57 


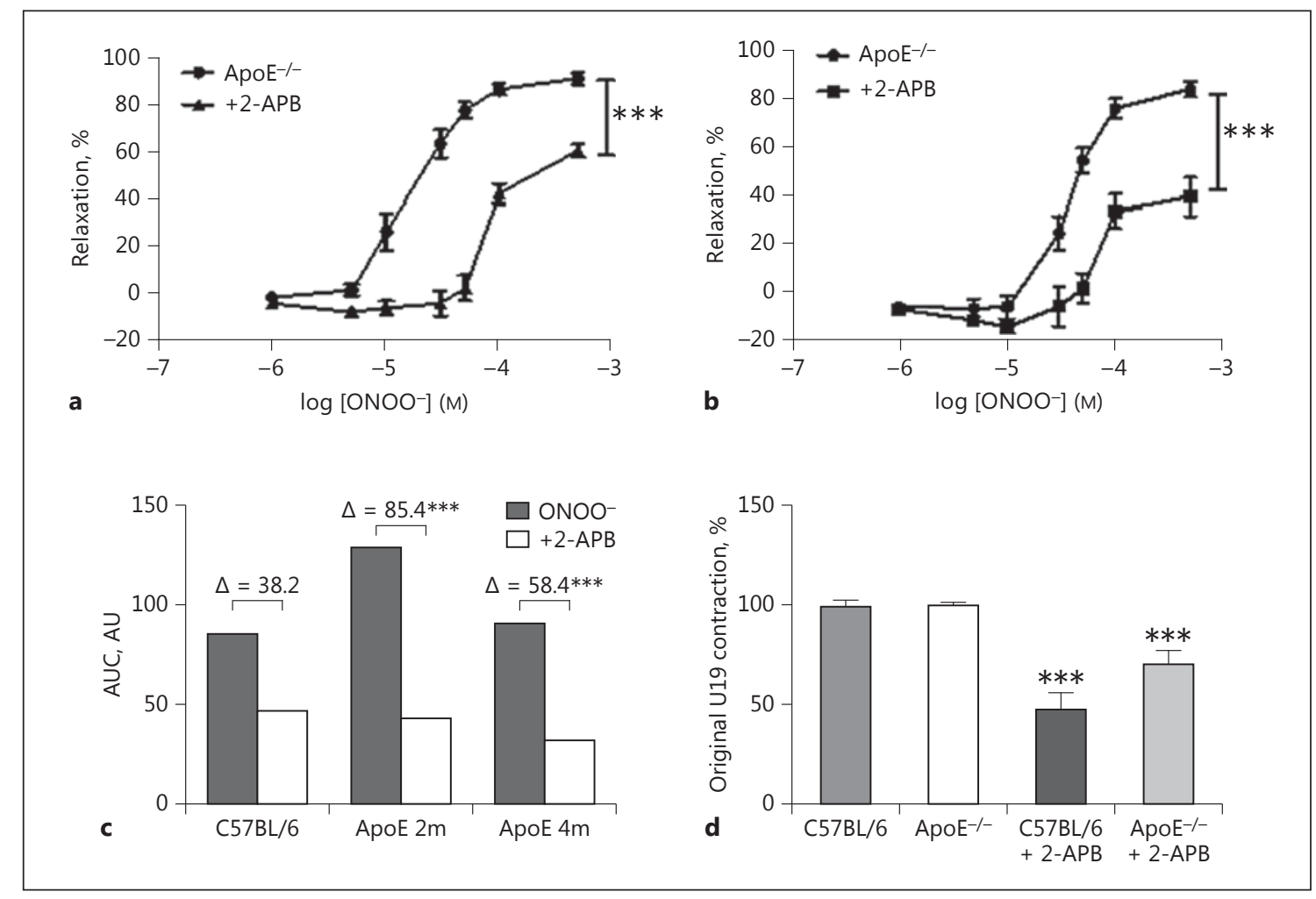

Fig. 2. a In $\mathrm{ApoE}^{-/-}$mice fed a high-fat diet for 2 months, 2-APB $(60 \mu \mathrm{M})$ caused a significant attenuation of relaxation to peroxynitrite. b After 4 months of a high-fat diet, 2-APB still caused a significant attenuation of relaxation to peroxynitrite. $\mathbf{c}$ The degree of inhibition caused by 2-APB was compared in C57BL/6 and $\mathrm{ApoE}^{-}$ ${ }^{1-}$ mice by measuring the area under the curves (AUC) and the difference between these areas. 2-APB had a significantly greater in- hibitory effect in $\mathrm{ApoE}^{-/-}$at both 2 and 4 months compared to C57BL/6 mice. $\mathbf{d}$ The addition of 2 -APB reduced contraction of aortic rings to 9,11-dideoxy-9a,11a-methanoepoxy prostaglandin $\mathrm{F}_{2 \alpha}$ (U46619), but the effect was less marked in $\mathrm{ApoE}^{-/-}$mice. $2 \mathrm{~m}$, 2 months of high-fat feeding; $4 \mathrm{~m}, 4$ months of high-fat feeding. *** $p<0.001$ vs. the ApoE ${ }^{-/-}$control group. $n>5$ for all groups. and $\mathrm{ApoE}^{-/-}$mice, the area under the dose-response curve in the presence and absence of 2-APB was measured using GraphPad Prism software and the difference between the two curves was calculated. This demonstrated that the degree of inhibition by 2 -APB was significantly greater in mice fed a high-fat diet for 2 and 4 months compared to $\mathrm{C} 57$ mice. The area under the curve was 128.9 vs. 43.0 after 2 months of $\operatorname{diet}(\Delta 85.9 ; 66.6 \%$ reduction caused by 2 -APB) and 90.4 vs. 32.0 after 4 months of $\operatorname{diet}(\triangle 58.4 ; 64.6 \%$ reduction caused by 2 -APB $)$ compared to 84.9 vs. $46.7(\Delta 38.2 ; 45.0 \%$ reduction caused by $2-A P B)$ in C57 mice (data are summarized in Fig. 2c and comparative $\mathrm{EC}_{50}$ and $\mathrm{E}_{\max }$ values are given in online suppl. Table 1; see www.karger.com/doi/10.1159/000461581 for all online suppl. material). 2-APB incubation also reduced the contractile response of the aortic ring to U46619 in both $\mathrm{C} 57$ and $\mathrm{ApoE}^{-/-}$mice with a non-significant trend towards a larger reduction in $\mathrm{ApoE}^{-/-}$mice (Fig. 2d).
In contrast to $\mathrm{ONOO}^{-}[6]$, the sensitivity of the aorta to relaxation by cromakalim was significantly attenuated in $\mathrm{ApoE}^{-/-}$mice after 4 months of fat-feeding, with a nonsignificant trend towards reduced sensitivity at 2 months (Fig. 3a). A similar attenuation caused by fat-feeding on aortic relaxation to other vasodilators such as the AMPK activating agent A769662 has also been observed by us previously [19]. Relaxation to A769662 was partly dependent on IP3R activation since it was significantly attenuated by the very selective IP3R antagonist xestospongin $\mathrm{C}$ $(5 \mu \mathrm{M})$ in C57 mice (Fig. 3b) and also in $\mathrm{ApoE}^{-/-}$mice on the diet for 4 months (Fig. 3c).

In VSMC, IP3, through activation of IP3R1 can activate large-conductance calcium-activated potassium channels in the plasma membrane independently of the SR calcium release, leading to hyperpolarization and vasodilatation [4]. This may serve to limit vasoconstriction in response to IP3R activation and may underlie the at- 


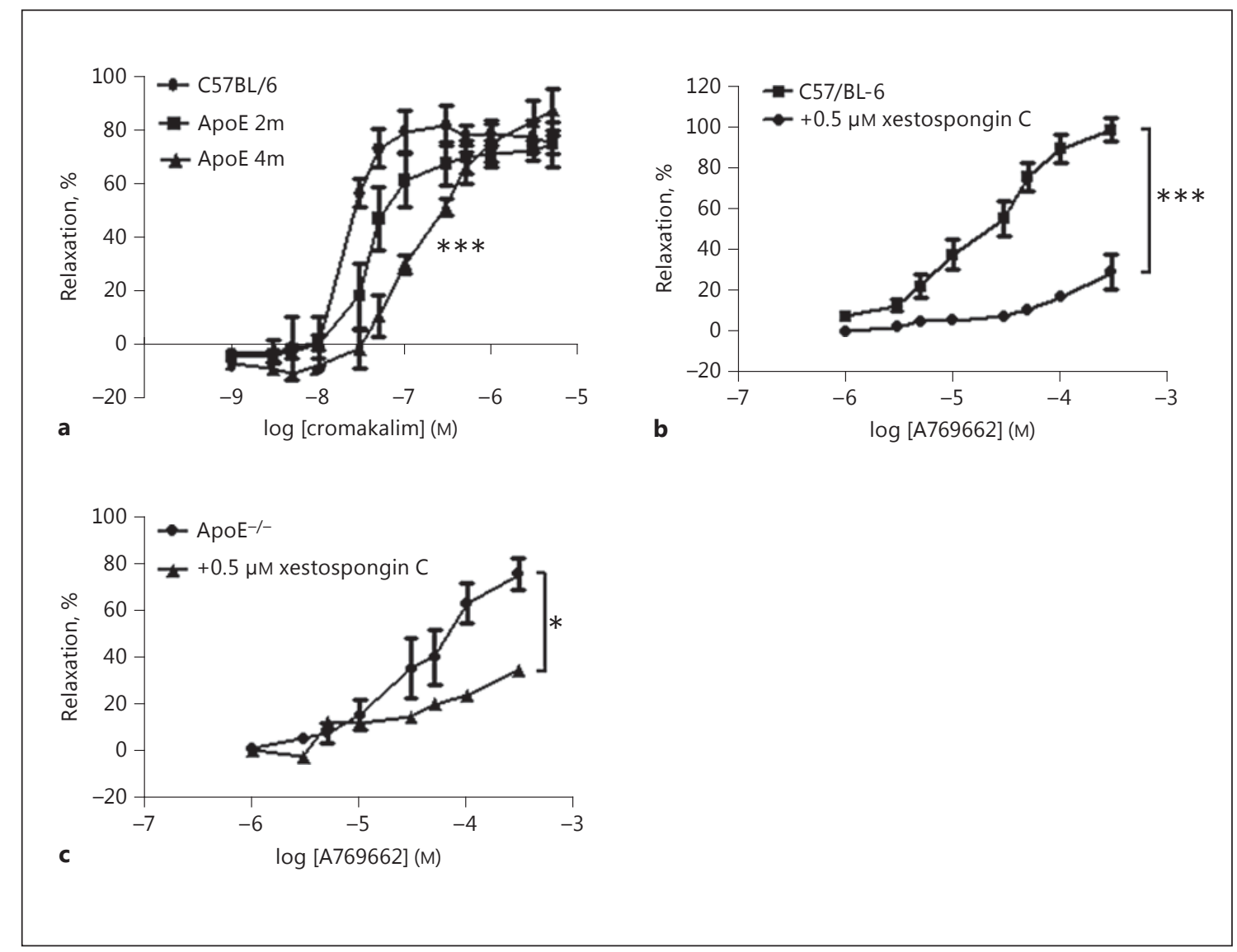

Fig. 3. a The high-fat diet caused a progressive reduction in the sensitivity of aortic rings to the vasodilator cromakalim and this reached significance after 4 months of diet. ${ }^{* * *} p<0.001$ vs. the $\mathrm{C} 57 \mathrm{BL} / 6^{-}$control group. $\mathbf{b}$ In $\mathrm{C} 57 \mathrm{BL} / 6$ mice, vasodilation in response to the AMPK activating agent A769662 was attenuated by the IP3 receptor antagonist xestospongin $\mathrm{C}(5 \mu \mathrm{M}) .{ }^{* * *} p<0.001$

tenuated vasodilation by IP3R antagonists in the current study. To test this, artery rings were treated with the non-selective calcium-activated potassium channel blocker TEA (1 $\mathrm{mM}$ for $30 \mathrm{~min}$ ) and dose-response curves to $\mathrm{ONOO}^{-}$repeated. TEA had no significant effect on the dose-response curve in C57 mice (Fig. 4a) but it did significantly reduce relaxation to $\mathrm{ONOO}^{-}$in ApoE $^{-/-}$mice after 2 and 4 months on a high-fat diet (Fig. 4b, c). TEA caused a rightwards shift of the doseresponse curve in $\mathrm{ApoE}^{-/-}$mice with significant increases in $\mathrm{EC}_{50}$ and no change in $\mathrm{E}_{\max }$ (see online suppl. Table 1). In agreement with the results in C57 mice, iberiotoxin had no effect on relaxation in 4 month fat-fed ApoE ${ }^{-/-}$mice (Fig. 4d), while 4-AP significantly attenuated relaxation but to a lesser degree than that seen in C57BL/6 mice (Fig. 4d).

IP3R and Atherosclerosis vs. the $\mathrm{C} 57 \mathrm{BL} / 6$ control group. $\mathrm{c}$ In $\mathrm{ApoE}^{-/-}$mice on the diet for 4 months, relaxation to A769662 was also significantly reduced by $5 \mu \mathrm{M}$ xestospongin C. ${ }^{*} p<0.05$ vs. the ApoE ${ }^{-/-}$control group. $n>$ 3 for all groups. $2 \mathrm{~m}, 2$ months of high-fat feeding; $4 \mathrm{~m}, 4$ months of high-fat feeding.

Together these data suggest that in mouse aorta, peroxynitrite induces relaxation in denuded vessels partly through activation of IP3R and membrane hyperpolarization via $\mathrm{K}_{\mathrm{v}}$ channels.

\section{Histological Analysis of IP3 Expression}

To study this further, we performed immunostaining for IP3R expression in paraffin-embedded samples of aorta. Only background staining was present in blank slides without antibody (Fig. 5a, b; the staining intensity

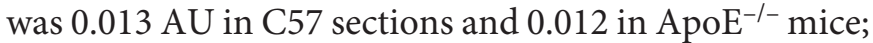
$n=3)$. In $\mathrm{ApoE}^{-/-}$mice on the diet for 4 months, the expression of IP3R1 was clearly reduced in medial SMC compared to $\mathrm{C} 57$ mice (Fig. $5 \mathrm{c}$, d; the staining intensity averaged 0.109 $\mathrm{AU}$ in C57 mice vs. $0.043 \mathrm{AU}$ in $\mathrm{ApoE}^{-/-}$ mice). 


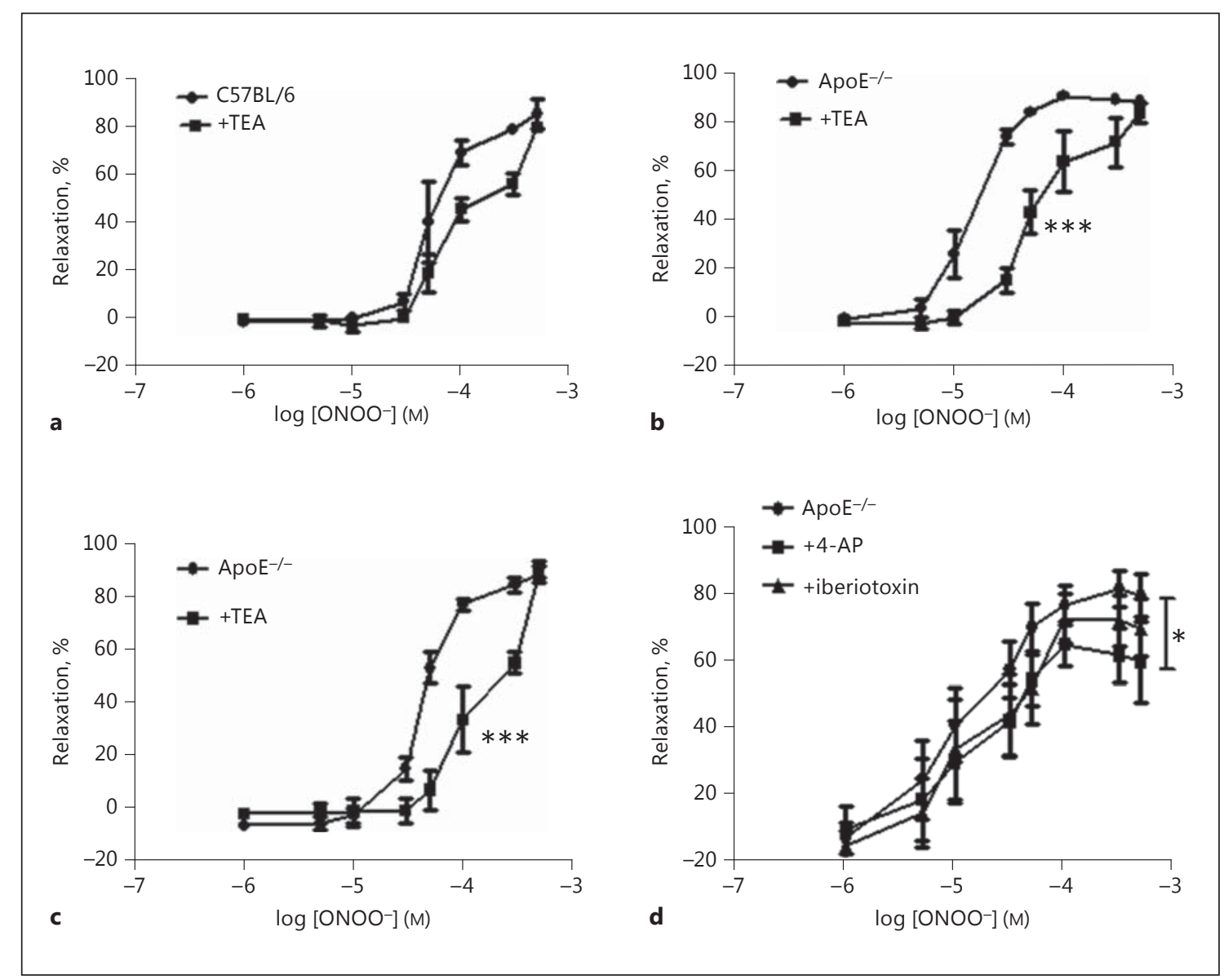

Fig. 4. a Relaxation to peroxynitrite in $\mathrm{C} 57 \mathrm{BL} / 6$ mice was not significantly different following treatment with $1 \mathrm{mM}$ of the calciumactivated potassium channel blocker TEA. b In $\mathrm{ApoE}^{-/-}$mice fed diet for 2 months, TEA caused a significant rightwards shift of the dose-response curve. c A significant rightward shift in response to
$1 \mathrm{mM}$ TEA was also observed in $\mathrm{ApoE}^{-/-}$mice on a high fat diet for 4 months. $\mathbf{d}$ Iberiotoxin had no effect on relaxation in 4 month fatfed $\mathrm{ApoE}^{-/-}$mice while 4-AP significantly attenuated relaxation but to a lesser degree than that seen in C57BL/6 mice. ${ }^{*} p<0.05$ and ${ }^{* * *} p<0.001 \mathrm{vs} \mathrm{ApoE}^{-/-}$control group, $n>3$ for all groups.

\section{Protein Expression/Immunoblotting}

To further demonstrate the reduction of IP3R expression in vascular tissue caused by fat-feeding, whole aortic homogenates were probed using antibodies to IP3R1. $\mathrm{ApoE}^{-/-}$on the diet for 2 months showed no significant change in IP3R1 expression, but after 4 months on the diet there was a dramatic reduction in IP3R1 protein expression (Fig. 6a, b). Since activation of IP3R can open membrane $\mathrm{BK}_{\mathrm{Ca}}$ channels to induce hyperpolarization, we measured expression of $\mathrm{BK}_{\mathrm{Ca}}$ in aortic homogenates from 3 pooled samples from $\mathrm{C} 57$ and $\mathrm{ApoE}^{-/-}$mice on the diet for 2,3 , or 4 months. Compared to $\mathrm{C} 57, \mathrm{BK}_{\mathrm{Ca}}$ expression was markedly elevated in $\mathrm{ApoE}^{-/-}$mice after both 2 and 3 months of fat-feeding but had declined by 4 months (Fig. 6c, d).

\section{Discussion}

In this study we demonstrated that relaxation to peroxynitrite in endothelium-denuded mouse aortic rings is partly mediated through activation of IP3R and opening of $\mathrm{K}_{\mathrm{v}}$ potassium channels. As atherosclerosis develops, the relaxation to $\mathrm{ONOO}^{-}$is maintained and becomes more dependent on IP3 activation despite a reduced expression of IP3R protein and a reduced importance of the $\mathrm{K}_{\mathrm{v}}$ channel. Upregulation of $\mathrm{BK}_{\mathrm{Ca}}$ potassium channels may compensate for lower IP3R levels in the aorta during the early stages (2-3 months) of atherosclerosis but do not appear to be involved in vasorelaxation in C57 mice or in atherosclerotic mice after 4 months of a high-fat diet. We speculate that relaxation is maintained through increased extrusion of calcium via PMCA [6] and this 
Fig. 5. Immunostaining for IP3 receptor expression in $\mathrm{C} 57 \mathrm{BL} / 6(\mathbf{a}, \mathbf{b})$ and $\mathrm{ApoE}^{-/-}$ (c, d) aortic rings. Aortae were removed from $\mathrm{ApoE}^{-/-}$mice on the diet for 4 months and age-matched C57 mice. No staining was visible in arteries in which the primary antibody was omitted (a, c). IP3 receptor was diffusely expressed throughout the medial layer in C57BL/6 mice (b), with a clear reduction in receptor expression in the high-fat-fed ApoE ${ }^{-l-}$ mice (d). Representative images are shown, with a minimum of 4 arteries studied for each group. Scale bars, $10 \mu \mathrm{m}$.

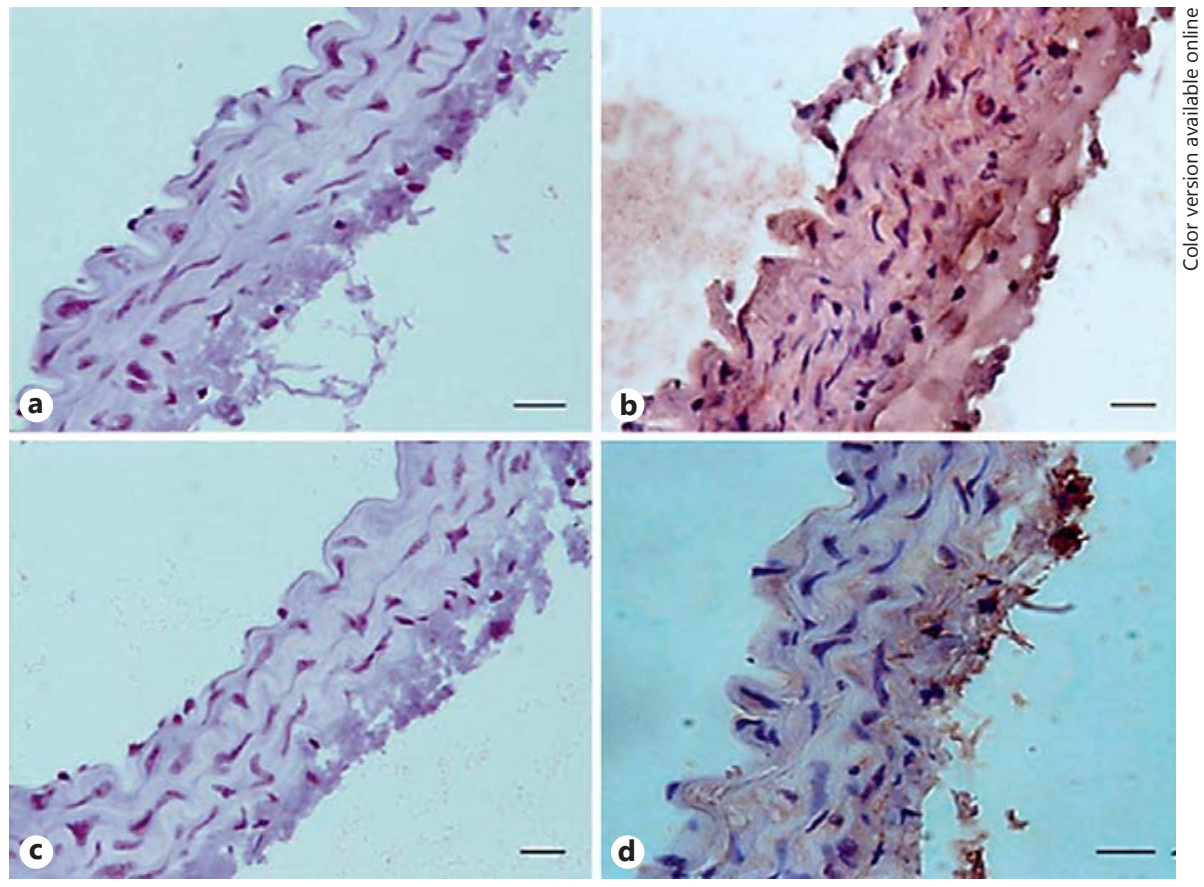

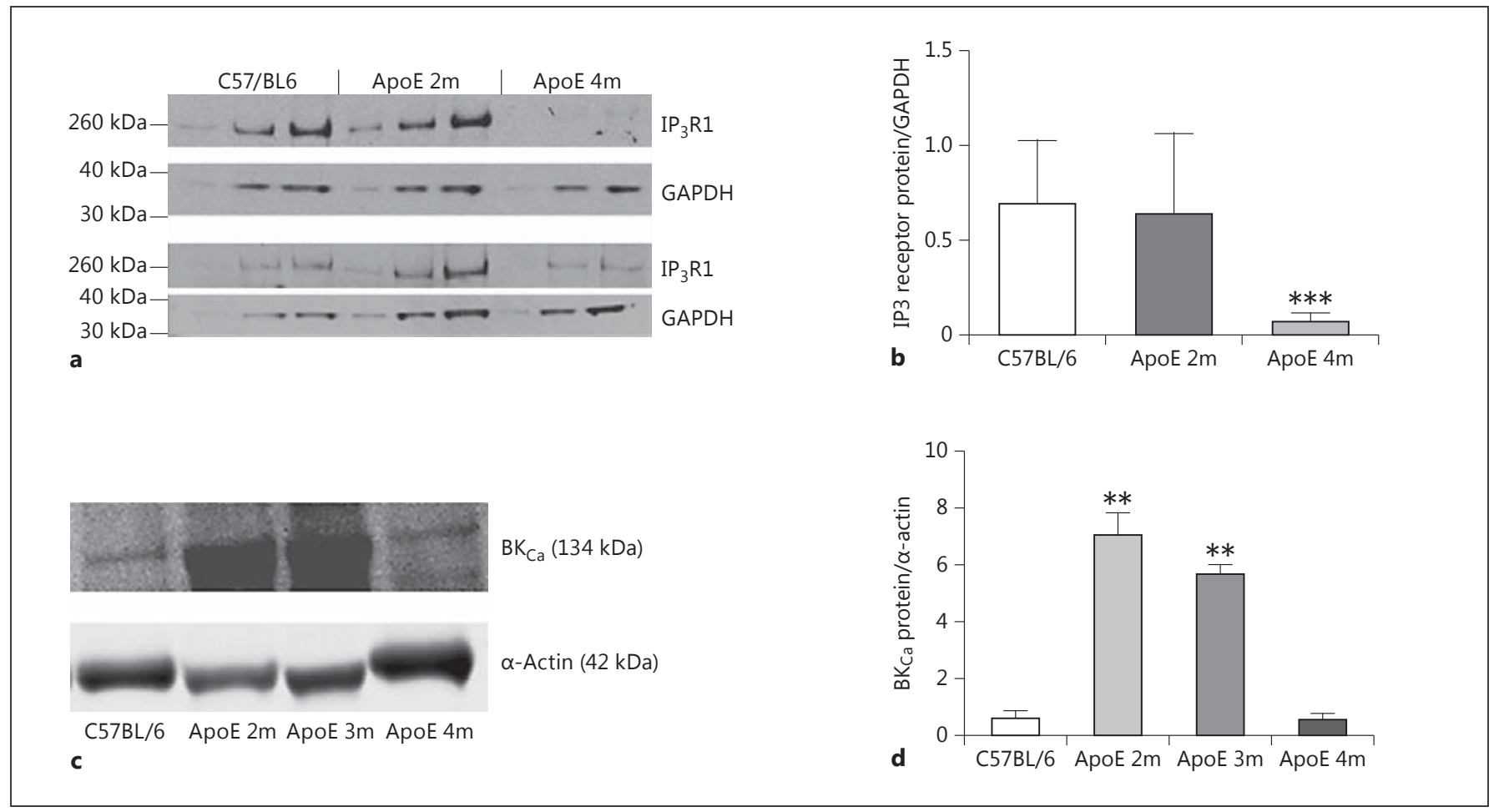

Fig. 6. Western blotting was used to quantify the effect of a high-fat diet on IP3 and $\mathrm{BK}_{\mathrm{Ca}}$ channel expression in aortic homogenates. a, b For IP3 expression, 3 different protein loads were added in adjacent lanes for each sample, with GAPDH used as the housekeeping gene. Two representative blots are shown. b Histogram showing a significant reduction in IP3 receptor expression after 4 months of a high-fat diet. $n=3$. ${ }^{* * *} p<0.001$ vs. the C57BL/ 6 group. c, d For $\mathrm{BK}_{\mathrm{Ca}}$ expression, $\boldsymbol{\alpha}$-actin was used as the housekeeping gene. $\mathbf{d}$ Histogram showing a significant increase in $\mathrm{BK}_{\mathrm{Ca}}$ expression in aortic homogenates from $\mathrm{ApoE}^{-/-}$on the diet for 2-3 months, with no significant change at 4 months. Representative blots are shown. $n=3{ }^{* *} p<0.01$ vs. the C57BL/ 6 group. $2 \mathrm{~m}, 2$ months of high-fat feeding; $3 \mathrm{~m}, 3$ months of high-fat feeding; $4 \mathrm{~m}$, 4 months of high-fat feeding. 
maintenance of relaxation is not shared with other endothelium-independent vasodilators such as cromakalim and the AMPK activator A769662.

In all experiments, we pre-contracted aortic rings with the thromboxane $\mathrm{A}_{2}$ mimetic U46619. Thromboxane (and mimetics) contracts vascular smooth muscle by binding to specific G-protein-coupled receptors (TP receptors) and increasing cytosolic calcium via release from the SR. In the denuded rat pulmonary artery, contraction to U46619 was sensitive to 2-APB between 10 and $30 \mu \mathrm{M}$ [20], similar to the findings in the present study (Fig. 2c). Interestingly, in $\mathrm{ApoE}^{-/-}$mice fat-fed for 3 months, contraction to U46619 was less sensitive to $2-\mathrm{APB}$, and this is likely due to a reduced expression of IP3R in the $\mathrm{ApoE}^{-/-}$aorta (Fig. 6). Contraction to U46619 was unchanged in the absence of 2-APB, suggesting that calcium release via non-IP3R-mediated mechanisms or calcium entry may sustain the contraction in the $\mathrm{ApoE}^{-/-}$mouse.

In a previous study [6] also using $\mathrm{ApoE}^{-/-}$mouse aortic tissue, we demonstrated compensation in calcium regulation within aortic VSMC. In $\mathrm{ApoE}^{-/-}$mice, a reduction of SERCA expression was balanced by upregulation of the calcium-extruding pump PMCA, and this may explain why vasodilation to $\mathrm{ONOO}^{-}$is maintained even in animals with extensive atherosclerotic lesions. Here we demonstrate that vasorelaxation to other vasodilators is not maintained. This is likely related to the mechanisms of vasodilation in response to A769772 and cromakalim. A769772 activates the enzyme AMPK in the endothelium and the VSMC and in a previous study we found that only 6 weeks of fat-feeding were sufficient to lower both total and phosphorylated AMPK expressions in the aorta compared to control mice [19]. Thus, the reduction of target enzyme levels could explain the reduced relaxation to A769772 in atherosclerotic mice. The progressively decreased sensitivity to cromakalim in $\mathrm{ApoE}^{-/-}$mice on a high-fat diet for 2 and 4 months was a surprising finding. Cromakalim hyperpolarizes the SMC membrane by opening $\mathrm{K}_{\mathrm{ATP}}$ channels and thereby decreasing the L-type $\mathrm{Ca}^{2+}$ channel opening time [21]. Previous studies have reported increases in sensitivity to cromakalim in hypertensive rats [22], while in hypercholesterolaemic rabbits dilation of the mesenteric artery in response to in vivo administration of cromakalim was preserved [23]. However, more recent studies have found that superoxide production by NADPH oxidase in the vascular wall can impair ATP-sensitive $\mathrm{K}^{+}$channel function and relaxation to levcromakalim can be augmented by free radical scavengers [24]. In the $\mathrm{ApoE}^{-/-}$mouse, oxidant stress in the ves- sel wall is progressively increased [6] and this could underlie the reduced sensitivity of the vessel to cromakalim. Since relaxation to $\mathrm{ONOO}^{-}$was unaffected by the $\mathrm{K}_{\mathrm{ATP}}$ antagonist glibenclamide, any impairment in the function of the $\mathrm{K}_{\mathrm{ATP}}$ channel as atherosclerosis develops would not be expected to affect relaxation to $\mathrm{ONOO}^{-}$.

Relaxation to $\mathrm{ONOO}^{-}$in the murine aorta was maintained during 5 months of fat-feeding [6] and it was attenuated by the IP3R antagonists 2-APB and xestospongin (Fig. 1, 2). In rat aortic rings, the mechanism of $\mathrm{ONOO}^{-}$-induced relaxation involves opening of $\mathrm{K}^{+}$channels and membrane hyperpolarization [8]. We hypothesized that increases in intracellular calcium (perhaps via activation of IP3R) activate calcium-activated potassium channels on the cell membrane, leading to hyperpolarization and relaxation. In C57 aortic rings, only the $\mathrm{K}_{\mathrm{v}}$ channel blocker 4-AP attenuated relaxation to peroxynitrite while the selective $\mathrm{BK}_{\mathrm{Ca}}$ blocker iberiotoxin had no effect and TEA caused only a non-significant rightward shift of the dose-response curve.

In contrast, TEA significantly attenuated relaxation to $\mathrm{ONOO}^{-}$in $\mathrm{ApoE}^{-/-}$mice at 2 and 4 months, suggesting that opening of calcium-activated potassium channels becomes more important as atherosclerosis develops. However, TEA can also block a number of $\mathrm{K}_{\mathrm{V}}$ channels and it is possible that changes in the expression of these channels were responsible for the effects seen. In support of this, iberiotoxin failed to attenuate relaxation in $\mathrm{ApoE}^{-/-}$mice at 4 months and the attenuation caused by the $\mathrm{K}_{\mathrm{V}}$ channel blocker 4-AP was reduced (Fig. 4d). Taken together, this indicates that although the expression of potassium channels changes during atherosclerosis, this is not responsible for maintaining the relaxation to $\mathrm{ONOO}^{-}$.

The lack of effect of the $\mathrm{BK}_{\mathrm{Ca}}$ channel blocker iberiotoxin was somewhat surprising. Other studies have found that $\mathrm{ONOO}^{-}$generates spontaneous transient outward current (STOC) via activation of $\mathrm{BK}_{\mathrm{Ca}}$ channels in rat arteriolar SMC [25]. Pan et al. [25] found that an $\mathrm{ONOO}^{-}$ donor, i.e., SIN-1, induced a dose-dependent enhancement of STOC but 2-APB did not block the increase in STOC. They concluded that ryanodine receptor-mediated calcium release and influx from external sources activates STOC in response to $\mathrm{ONOO}^{-}$and that IP3R are not involved. Conversely, in porcine coronary artery SMC, activation of IP3R with IP3 itself activated $\mathrm{BK}_{\mathrm{Ca}}$ channels to enhance STOC and reduce the coronary artery tone [5].

It is possible that the regulation of potassium channels and STOC by intracellular calcium is very species specific or varies between vascular beds. Our data demon-
76

J Vasc Res 2017;54:68-78

DOI: $10.1159 / 000461581$
Ewart et al. 
strate that IP3R and $\mathrm{K}_{\mathrm{v}}$ channels are partly responsible for the relaxation to $\mathrm{ONOO}^{-}$in the mouse aorta and, as atherosclerosis develops, relaxation is maintained despite a reduced reliance on $\mathrm{K}_{\mathrm{v}}$-mediated hyperpolarization. To study this further, we investigated IP3R expression in artery homogenates. Surprisingly, in view of the preserved relaxation to $\mathrm{ONOO}^{-}$, we found a clear and significant reduction of IP3R protein expression in $\mathrm{ApoE}^{-/-}$mice after 4 months of fat-feeding (Fig. 6). Other studies have reported similar findings in VSMC exposed to oxidized LDL [26] and in atherosclerotic aorta [27]. However, in other disease states such as hypertension, there is evidence of upregulation of IP3R [28] as well as changes in the density of $\mathrm{K}^{+}$currents, with a switch to predominantly $\mathrm{BK}_{\mathrm{Ca}}$ currents in spontaneously hypertensive rats [29].

Since we previously demonstrated that $\mathrm{ApoE}^{-/-}$mice on a high-fat diet are hypertensive [19], we speculated that an increase in $\mathrm{BK}_{\mathrm{Ca}}$ channels on the aorta could compensate for the reduced IP3R expression and maintain relaxation to $\mathrm{ONOO}^{-}$. In pooled homogenates from 3 aortae, the expression of $\mathrm{BK}_{\mathrm{Ca}}$ channel protein was markedly upregulated in $\mathrm{ApoE}^{-/-}$mice on the diet for up to 3 months compared to control mice (Fig. 6). Although IP3 $\mathrm{R}$ and $\mathrm{BK}_{\mathrm{Ca}}$ channels are expressed on a wide variety of cells, the use of denuded aortae to produce the homogenates and the overwhelming propensity of VSMC in the homogenate make it likely that the changes in expression are at the level of the VSMC. If activation of IP3R is linked to STOC in the mouse aorta, upregulation of $\mathrm{BK}_{\mathrm{Ca}}$ may underlie the greater inhibitory effect of $2-\mathrm{APB}$ on $\mathrm{ONOO}^{-}$ -induced relaxation in $\mathrm{ApoE}^{-/}$aortae. In support of this, isolated SMC from human atherosclerotic plaques showed evidence of a higher $\mathrm{BK}_{\mathrm{Ca}}$ channel activity compared to normal medial SMC [30], and $\mathrm{BK}_{\mathrm{Ca}}$ channels appear to be much less sensitive than $\mathrm{K}_{\mathrm{v}}$ and $\mathrm{K}_{\mathrm{ATP}}$ channels to changes caused by oxidant stress [31], making them ideal candidates to compensate for the loss of other vasodilator mechanisms in disease states [32]. However, our data with iberiotoxin indicate that $\mathrm{BK}_{\mathrm{Ca}}$ is not involved in relaxation to $\mathrm{ONOO}^{-}$in the $\mathrm{C} 57$ mouse aorta or the $\mathrm{ApoE}^{-/-}$aorta after 4 months of fat-feeding. This does not rule out a role for $\mathrm{BK}_{\mathrm{Ca}}$ after 2 and 3 months of fat-feeding where the expression of $\mathrm{BK}_{\mathrm{Ca}}$ was upregulated; however, this seems unlikely and it appears that STOC and membrane hyperpolarization in response to $\mathrm{ONOO}^{-}$ is via $\mathrm{K}_{\mathrm{V}}$ and that this mechanism becomes less important in atherosclerotic mice. However, it should be noted that we did not study channel activity or measure intracellular calcium and so we cannot rule out changes in intracellular calcium from sources other than IP3R in the mouse aorta.

In conclusion, our study has shown that relaxation to peroxynitrite in C57BL/6 mouse aorta is partially mediated via IP3R activation and opening of $\mathrm{Kv}$ potassium channels. Although atherosclerosis attenuates the response to mechanistically dissimilar vasodilators, the response to $\mathrm{ONOO}^{-}$is maintained despite a progressive reduction in the expression of IP3R. Changes in the activity or expression of potassium channels during the development of atherosclerosis and increases in calcium extrusion via PMCA [11] may maintain relaxation to $\mathrm{ONOO}^{-}$. These compensatory changes in VSMC probably serve to limit detrimental changes in responsiveness under hyperlipidaemic conditions.

\section{Acknowledgement}

This study was funded by a project grant awarded by the British Heart Foundation (grant No. PG/07/012/22342).

\section{Disclosure Statement}

The authors declare that they have no conflict of interests.

\section{References}

- 1 Urena J, Fernández-Tenorio M, PorrasGonzález C, González-Rodríguez P, Castellano A, López-Barneo J: A new metabotropic role for L-type $\mathrm{Ca}^{2+}$ channels in vascular smooth muscle contraction. Curr Vasc Pharmacol 2013;11:490-496.

$>2$ Leung F, Yung L, Yao X, Laher I, Huang Y: Store-operated calcium entry in vascular smooth muscle. Br J Pharmacol 2008;153: 846-857.

IP3R and Atherosclerosis

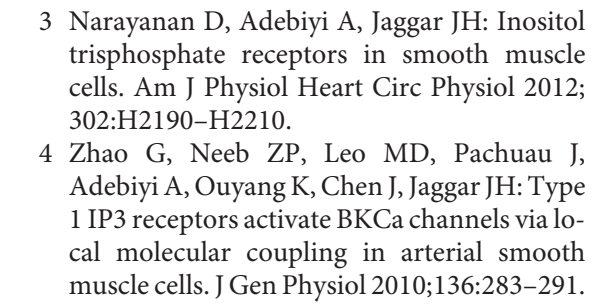

5 Yang Y, Li P-Y, Cheng J, Cai F, Lei M, Tan X-Q, Li M-L, Liu Z-F, Zeng X-R: IP3 decreases coronary artery tone via activating the $\mathrm{BK}$ Ca channel of coronary artery smooth muscle cells in pigs. Biochem Biophys Res Commun 2013;439:363-368.

-6 Ewart M-A, Kennedy S, MacMillan D, Raja AL, Watt IM, Currie S: Altered vascular smooth muscle function in the ApoE knockout mouse during the progression of atherosclerosis. Atherosclerosis 2014;234:154-161. 
7 Gheddouchi S, Mokhtari-Soulimane N, Merzouk H, Bekhti F, Soulimane F, Guermouche B, Tani AM, Narce M: Low SOD activity is associated with overproduction of peroxynitrite and nitric oxide in patients with acute coronary syndrome. Nitric Oxide 2015;49: 40-46.

$>8$ Li J, Li W, Altura BT, Altura BM: Peroxynitrite-induced relaxation in isolated rat aortic rings and mechanisms of action. Toxicol Appl Pharmacol 2005;209:269-276.

$\checkmark 9$ Adachi T, Weisbrod RM, Pimentel DR, Ying J, Sharov VS, Schöneich C, Cohen RA: S-glutathiolation by peroxynitrite activates SERCA during arterial relaxation by nitric oxide. Nat Med 2004;10:1200-1207.

10 Van Assche T, Fransen P, Guns P-J, Herman A, Bult $\mathrm{H}$ : Altered $\mathrm{Ca}^{2+}$ handling of smooth muscle cells in aorta of apolipoprotein E-deficient mice before development of atherosclerotic lesions. Cell Calcium 2007;41:295302.

11 Gleason MM, Medow M, Tulenko TN: Excess membrane cholesterol alters calcium movements, cytosolic calcium levels, and membrane fluidity in arterial smooth muscle cells. Circ Res 1991;69:216-227.

-12 Abou-Saleh H, Pathan AR, Daalis A, Hubrack S, Abou-Jassoum H, Al-Naeimi H, Rusch NJ, Machaca K: Inositol 1,4,5-trisphosphate (IP3) receptor up-regulation in hypertension is associated with sensitization of $\mathrm{Ca}^{2+}$ release and vascular smooth muscle contractility. J Biol Chem 2013;288:32941-32951.

13 Tada T, Nawata J, Wang H, Onoue N, Zhulanqiqige D, Ito K, Sugimura K, Fukumoto Y, Shimokawa H: Enhanced pulsatile pressure accelerates vascular smooth muscle migration: implications for atherogenesis of hypertension. Cardiovasc Res 2008;80:346-353.

14 Beech DJ: Orail calcium channels in the vasculature. Pflügers Arch 2012;463:635-647.

$\checkmark 15$ Weingartner O, Husche C, Schott HF, Speer T, Bohm M, Miller CM, McCarthy F, Plat J, Lutjohann D, Laufs U: Vascular effects of oxysterols and oxyphytosterols in apoE $\mathrm{E}^{-/-}$mice. Atherosclerosis 2015;240:73-79.
16 Cool B, Zinker B, Chiou W, Kifle L, Cao N, Perham M, Dickinson R, Adler A, Gagne G, Iyengar R: Identification and characterization of a small molecule AMPK activator that treats key components of type 2 diabetes and the metabolic syndrome. Cell Metab 2006;3: 403-416.

17 Miyamoto S, Izumi M, Hori M, Kobayashi M, Ozaki H, Karaki H: Xestospongin C, a selective and membrane-permeable inhibitor of $\mathrm{IP}(3)$ receptor, attenuates the positive inotropic effect of alpha-adrenergic stimulation in guinea-pig papillary muscle. Br J Pharmacol 2000;130:650-654.

18 Huang S, Pang L: Comparing statistical methods for quantifying drug sensitivity based on in vitro dose-response assays. Assay Drug Dev Technol 2012;10:88-96.

19 Greig FH, Ewart M-A, McNaughton E, Cooney J, Spickett CM, Kennedy S: The hypotensive effect of acute and chronic AMP-activated protein kinase activation in normal and hyperlipidemic mice. Vascul Pharmacol 2015;74:93-102.

20 McKenzie C, MacDonald A, Shaw AM: Mechanisms of U46619-induced contraction of rat pulmonary arteries in the presence and absence of the endothelium. Br J Pharmacol 2009; 157:581-596.

21 Quayle JM, Bonev AD, Brayden JE, Nelson MT: Pharmacology of ATP-sensitive $\mathrm{K}^{+}$currents in smooth muscle cells from rabbit mesenteric artery. Am J Physiol 1995;269:C1112C1118.

22 Kinoshita H, Kakutani T, Iranami H, Hatano $\mathrm{Y}$ : The role of oxygen-derived free radicals in augmented relaxations to levcromakalim in the aorta from hypertensive rats. Jpn J Pharmacol 2001;85:29-33.

23 Rozsa Z, Pataricza J, Nemeth J, Papp JG: Differential efficacy of vasodilators in hypercholesterolaemic rabbits. J Pharm Pharmacol 1998;50:1035-1044.
4 Haba M, Kinoshita H, Matsuda N, Azma T, Hama-Tomioka K, Hatakeyama N, Yamazaki M, Hatano Y: Beneficial effect of propofol on arterial adenosine triphosphate-sensitive $\mathrm{K}^{+}$ channel function impaired by thromboxane. Anesthesiology 2009;111:279-286.

25 Pan B-X, Zhao G-1, Huang X-1, Zhao K-S: Calcium mobilization is required for peroxynitrite-mediated enhancement of spontaneous transient outward currents in arteriolar smooth muscle cells. Free Radic Biol Med 2004;37:823-838.

26 Massaeli H, Austria JA, Pierce GN: Overexpression of SERCA2 ATPase in vascular smooth muscle cells treated with oxidized low density lipoprotein. Mol Cell Biochem 2000; 207:137-141.

27 Ewart M-A, Currie S, McCarron JG, Kennedy $S$ : Altered calcium handling between healthy and atherosclerotic vascular smooth muscle. Biophys J 2009;96:117a.

28 Guillemette G, Bernier S: Increased inositol 1,4,5-trisphosphate binding capacity in vascular smooth muscle of spontaneously hypertensive rats. Am J Hypertens 1993;6:217-225.

29 Zhang Y, Gao Y-J, Zuo J, Lee RM, Janssen LJ: Alteration of arterial smooth muscle potassium channel composition and BK Ca current modulation in hypertension. Eur J Pharmacol 2005;514:111-119.

30 Wiecha J, Schläger B, Voisard R, Hannekum A, Mattfeldt T, Hombach V: $\mathrm{Ca}^{2+}$-activated $\mathrm{K}^{+}$channels in human smooth muscle cells of coronary atherosclerotic plaques and coronary media segments. Basic Res Cardiol 1997; 92:233-239.

>31 Terata K, Coppey L, Davidson E, Dunlap J, Gutterman D, Yorek M: Acetylcholine-induced arteriolar dilation is reduced in streptozotocin-induced diabetic rats with motor nerve dysfunction. Br J Pharmacol 1999;128: 837-843.

32 Liu Y, Gutterman DD: The coronary circulation in diabetes: Influence of reactive oxygen species on $\mathrm{K}^{+}$channel-mediated vasodilation. Vascul Pharmacol 2002;38:43-49. 